\title{
A study on the domain of passive income strategies in architecture and how the confluence of entrepreneurship and architecture can transform the design \\ practice \\ Mansanjam Kaur ${ }^{1}$, Pragya Kher ${ }^{2}$, Aanchal Khandelwal ${ }^{3}$, Simar Paul ${ }^{4}$, Shruti S. Nagdeve ${ }^{5^{*}}$ \\ ${ }^{1,2,3,4}$ Students, School of Planning and Architecture, New Delhi, India; ${ }^{5 *}$ Research Scholar, School of Planning and Architecture, New Delhi, India. \\ Email: ${ }^{1}$ mansanjam2939arch16@ spa.ac.in, ${ }^{2}$ greeshmikan@gmail.com, ${ }^{3}$ aanchal2892arch16@spa.ac.in, ${ }^{4}$ simar2984arch16@spa.ac.in, ${ }^{5^{*}}$ shruti197phd18@spa.ac.in
}

Keywords

Passive Income, Entrepreneurship,

Marketing, Income Generation.

Article History

Received on $14^{\text {th }}$ November 2021

Accepted on $17^{\text {th }}$ January 2022

Published on $5^{\text {th }}$ February 2022

Cite this article

Kaur, M., Kher, P., Khandelwal, A., Paul,

S., \& Nagdeve, S. S. (2022). A study on

the domain of passive income strategies in

architecture and how the confluence of

entrepreneurship and architecture can

transform the design practice.

International Journal of Students

Research in Technology \& Management,

10(1), 01-14.

https://doi.org/10.18510/ijsrtm.2022.1011

Copyright @ Author

Publishing License

This work is licensed under a Creative Commons Attribution-Share Alike 4.0 International License

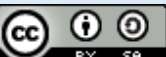

\section{Abstract}

Purpose of the study: Currently, in India, there is high growth in real estate and marketing in the urban sector. Architecture as a profession is still underrecognition and it is growing albeit slowly. Hence, there is a need towards developing a more interdisciplinary approach of merging entrepreneurship with the practice of architecture and other allied disciplines to create a passive source of income generation. Previous research looked at passive income as merely a source of retirement income generation strategy. This research aims to understand how passive income can be used as a branding tool and a means of active income generator.

Methodology: Various expert interviews were conducted to understand how passive income strategies fare in the real world and the gaps between the theory and implementation of these strategies. Successful case models, national and international, were also analysed.

Main Findings: There is a limited understanding regarding the opportunities which a passive source of income can offer. It is merely considered an additional source of income, overlooking the branding opportunities it entails. Apart from time and money, identifying one's strengths and skills is an important component in deciding on the kind of passive strategy one want's to invest in.

Implications: Passive source of income allows a person to explore a certain field and go an extra mile to analyze and choose the field to best of his/her opportunities. It is a revenue stream with one-time investment with time, money, skill and marketing which enables it as a passive and long term income. With the current generation dwelling more and more into a secondary source of income, this study may help understand the overall process undergoing a passive income strategy.

\section{INTRODUCTION - BACKGROUND AND NEED FOR STUDY}

Currently, in India, there is high growth in real estate and marketing in the urban sector. Architecture as a profession is still under-recognition. People are unaware of architects' jobs and professionally hiring an architect for a project is still doomed. Builders are mostly engaged to construct large projects. Hence the architecture profession is growing albeit slowly. So it is necessary to engage in Passive sources of income for architects.

Architectural education is an accepted reality that complements us with a broad range of skills, such as critical thinking and interpretation, Design ideation, hands-on development, thinking about research and so on. In real-life examples, we also see that providing excellent architectural services can not always guarantee a profitable architecture firm. Architects who can often build with utmost ease can fail as a revenue-generating profession to inrun this architectural practice. In such cases, using the skills and experience learned as architects to pick up and power Passive Income Ideas that can be taken forward along with our architecture practice is an ideal solution.

Passive source of income allows a person to explore a certain field and go an extra mile to analyze and choose the field to best of his/her opportunities. It is a revenue stream with one-time investment with time, money, skill and marketing which enables it as a passive and long term income.

Passive income requires effort and skill to be invested so take time to evolve and bring a huge upfront investment, this is a very helpful source of income that helps bridge the gap between the lesser earning in the field and exploring the skills. Current need of the hour in the professional field of architecture is to be explorative with the field in the various skills and Passive income can be a great money generation source once invested with time and effort with proper planning can function in the background autopilot mode. The Field of Architecture like other professional fields, one makes a decent income and explores the field by designing and drawing the project for buildings which can be stonebuilt or under renovation. But, as visible in the country as the current scenario, one thing is certain in architecture, earning revenue passively will benefit in many ways, including having a supplementary source and a nest egg. 
The research of the Passive source of income and the strategies involved in the field of architecture will help understand how one can start afresh and explore the field and gain perspective of different people in the field and their needs and requirements.

\section{Research Questions}

- What is passive income, why is it the need of the hour for architects?

- How do theoretical passive income ideas fare in the real world?

- To what extent can architects be labelled as entrepreneurs? And how does passive income supplement this role?

- How does passive income help in sustaining a better role in the field?

\section{Aim}

The research aims to study how to create Passive income in architecture through experience and talent and to analyze the implications of business and Marketing models in the creative field.

\section{Objectives}

- To identify the different ways architects and their group (co-workers, employees) can pitch for newer possible aspects in the field of 1 architecture.

- To analyse the successful models internationally and nationally to weigh out the pros and cons.

- Identifying the practicality and reality of the different kinds of passive income strategies.

\section{Scope}

The scope of the study shall focus on understanding the possible passive income strategies and their implications for senior architects and shall not take into account the possible strategies for the younger architects.

\section{Limitations}

It is beyond the scope of the study to conduct primary analysis for this research due to the pandemic situation. The study shall rely on secondary data sources only.

\section{PASSIVE INCOME IN A NUTSHELL}

Passive income is a secondary or an indirect source of income generated through a side venture with minimal work or one-time work and regular amount of effort and maintenance. (Carpenter, 2016), as defined by the Google Dictionary; Passive: not active, needing little or no of your time; Income: The money you receive regularly as payment for your work or as interest on the money you have saved, etc.(Google Dictionary)

Passive income is a side hustle when an individual or a group has a full-time job, business or the direct source of income, which is involved up to the major working hours. But an investment in some side venture through that skill and knowledge to run the passive income sources.Also, looking at the various examples in the real world shows that passive income is a hard and fast way to earn and survive. One needs a high amount of dedication and effort to make it grow and once grow it flourishes to the top. Once a passive income stream is developed with investing through a skill, money, time and risk involving factors, all this with a high amount of dedication, commitment, enthusiasm and effort can help sustain and scale it further.

The current speed of running off in a world where everything is time-based as we say time is money. The day and its hours remain constant and the human hustle to grow and flourish in the world increases. Passive income is all about having a side thing which gives an individual access to more money, it is all about based on time, rather than any other thing. As one does many things which are time-consuming if they are a source of some amount of income. Whereas with the Passive source of income it's all about the one-time investment of time and then it should pay back. The common doubt between the indirect and direct sources of income makes us question the basics of what all can be considered as passive sources and whatnot. To look at the various sources and then analyze what all can constitute in the passive sources of income.

If an individual requires the same or more time on a project or a work that too on a frequent and direct basis and that generated the same amount of financial outcome that is just another source of income, cannot be termed a passive source.

For a passive, so multitaskers as well very keenly invested with different kinds of explorative fields. People do tend to have various hustles and few of these can grow up into passive sources. The different age groups vary from the fresher and well-established professionals there is a need to have passive sources for future trust and security. Here are the few strategies which can be performed as a side hustle and passive; blogs, writings; Youtube tutorials, video making; $3 \mathrm{~d}$ rendering and services; Offering online courses; Freelancing; Indulging in product design; Participating in competitions and conferences; Architectural writing - e-books, articles; Online courses and lectures; Social Media - Marketing; Taking a stake Construction projects / investing in real estate projects; Project management and site supervision; Online courses- general management, marketing, CAD drawing, LEED exams, stability calculations, impact analysis; Carve a 
niche around your work; Selling your tools, code, spreadsheets, calculations and equipment to willing buyers; Sell Your Designs and House Plans- If we have drawn designs and plans, but didn't have them actualized or built, this is an idea you might want to consider. We can earn money passively by showcasing and selling our work online; Teaching; Investing in real estate.

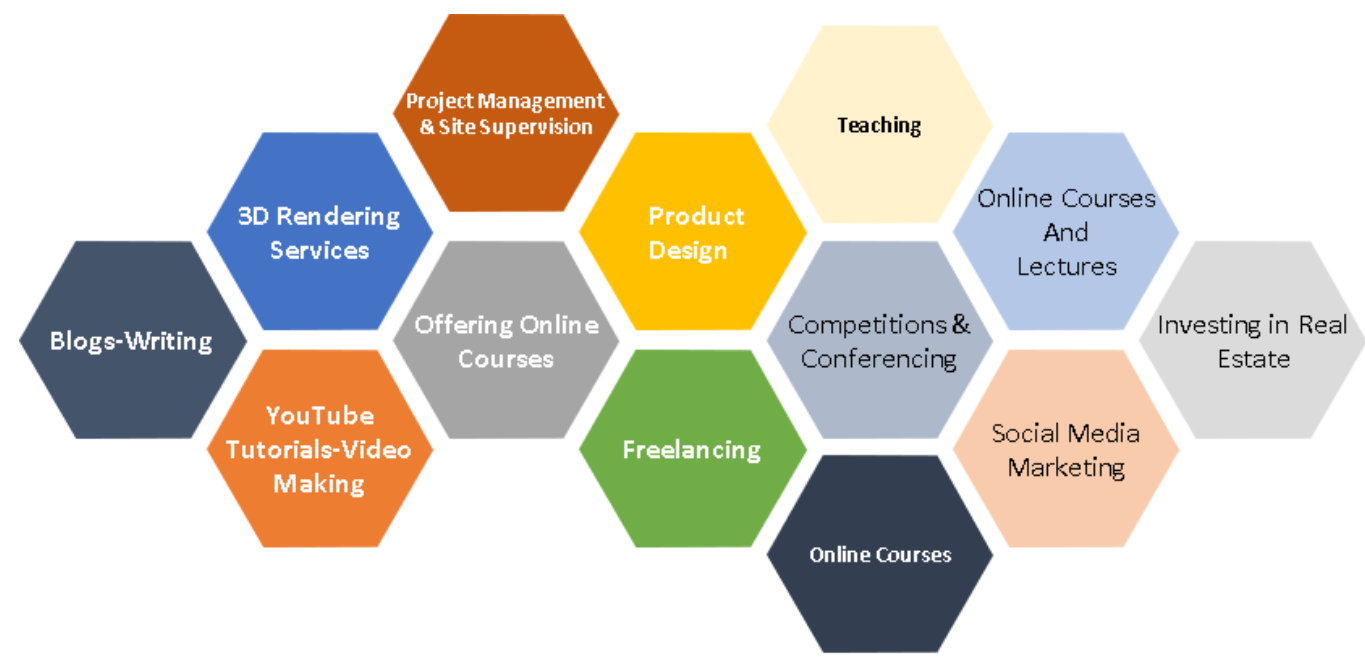

Alternative Passive Income Strategies

Figure 1: Alternative Passive Income Strategies

\section{Passive Income - One Time Investment strategies}

The various Passive sources of income which involve one-time investment strategies can be categorized as below:

\section{Advertising and online e-commissions}

Build content online for free (typically on the blog, Instagram) ss per the firm's expertise. Getting paid via links, banners, commissions and ads by monetizing the content and expanding further to be termed into greater brands.

\section{Book Writing}

Write a book on areas of expertise-like design, detailing or trade tricks, anything that reflects experience. Selling it online to as many people as possible generates passive monthly income.

\section{Industrial Design}

The architects can also tap an industrial design as a potential area of services as they understand the expectations and, hence, deliver a good service.

\section{Participate in competitions and conferences}

In addition to being a great way to advertise, these conferences and competitions reflect knowledge and talent along with company experience. This helps to create clients ready to pay more for good designers and architects.

\section{Online courses and lectures}

The principal architect could take up a teaching job at a reputed college to have steady revenue and re-establish links with the industry. The business may also start online courses or lectures to impart the bundles of information they have

\section{Take a stake in the construction industry.}

Real estate industry can also be tapped into as architects have a good understanding of the market. Own a part of the real estate that has worked and take a stake its future earnings

\section{Conducting workshops and site visits for young architects}

Since the firm has a workforce of 50 employers who have been working for a very long time, it is guaranteed that the skill set and knowledge of each person might be unique and being architects from a different generation, they might possess knowledge that the current generation of young architects may never even have heard of. So, one idea could be imparting this knowledge and wisdom to the emerging young minds so that they get to explore and analyse their design problems through a different lens and the added layers of this imparted knowledge. So, these workshops can include site visits where the students can be taught about the wide array of skills learned from our masons and carpenters. And since our firm has quite a good number of projects at hand and co-operating clients, this can be arranged quite easily. 


\section{One Time Investment Strategies}

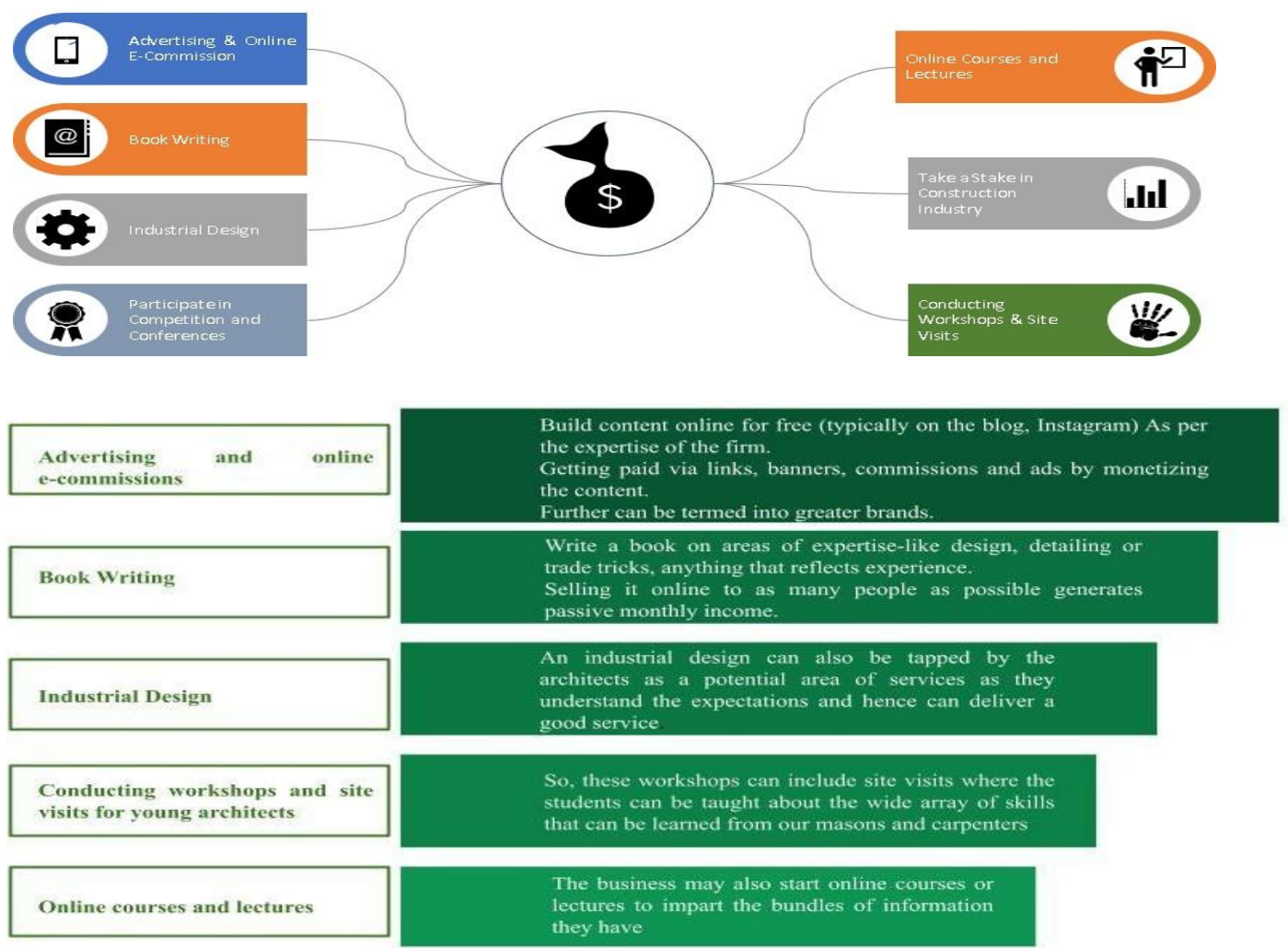

Figure 2: Shortlisted Passive Strategies

\section{Strategizing for an appropriate strategy for passive income}

Starting from an idea, the first stage is to establish the organisation's interests and strengths. This comprises of; Planning and devising a strategy; Project Investigation; Commercializing/promoting the idea; Working towards reinvention.

\section{Implementing the strategies}

Creating Passive Income ideas would require a few basic steps that include the following:

1. Starting With An Idea

2. Planning And Strategizing

3. Investing In The Project - Time, Money and Effort

4. Marketing Your Idea

5. Working To Launch and establish the success

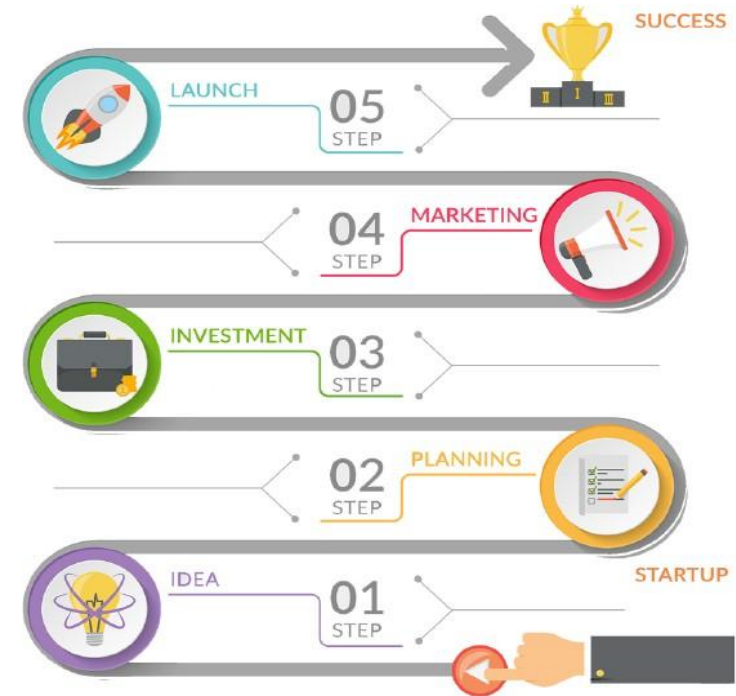

Figure 3: Implementation of Strategies 


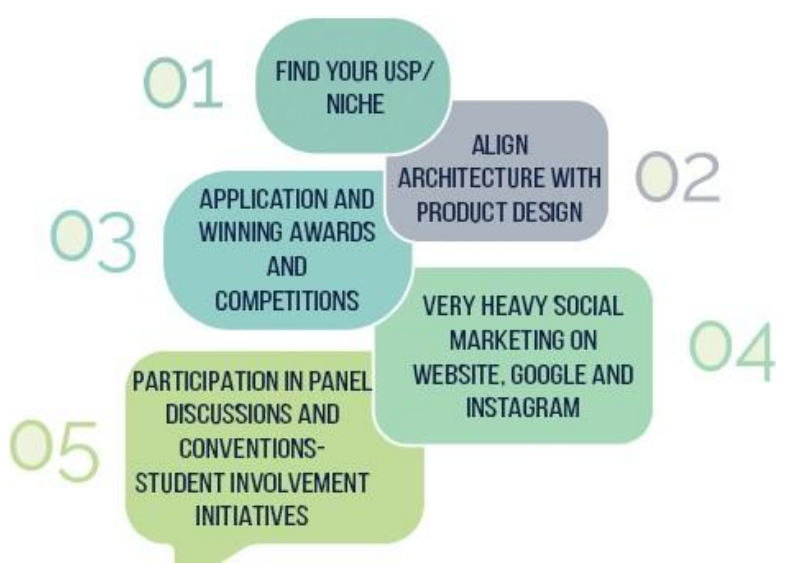

Figure 4: How to achieve the end results?

\section{ARCHITECTS TURNING ENTREPRENEURS (ARCHIPRENEUR)}

Buckminster Fuller, Zaha Hadid, Jonathan Segal, B.V Doshi are successful architects and brand names among themselves, The architectural marvels they have created are solutions to massive, highly complex design problems. Their enterprise's journey towards various findings and programmes is an ecosystem upon which they depended. These ecosystems comprise unique combinations of successful elements which they figured out during their respective journey, based on their respective callings, which later laid the foundation for their growth and development.

Their powerful vision has helped them create these unique ecosystems, but an ecosystem with integrated growth elements should be developed for the small, early emerging architects. A social entrepreneur is searching for an environment to combine their innovations and release the finished product/result, what is common between the two is that the architect is also on a similar quest and architects are still looking for a similar solution.

We see over 4,000 students per year and over 60,000 architects have been registered in India to date. If we know that $5,00,000$ architects are required to meet the growing demands of Indian clients, these figures seem disturbing.

There is a lack of an environment that supports dependency in India, while there has been a spillover in demand and thus a rise in dependence on architects in immobilisation and construction industries is observed. Professional and innovative Architects are also not easily accessible to consumers, adding to that neither their work/portfolio and reputation in the market is known to the consumers.

Elements of an ecosystem for Architects in India

Networking, a forum for exchanging views, access to key information, opportunities for branding and promotion, ongoing professional growth and critical skills are a few things necessary for an architect to thrive.

1. Consumer Education: A significant boon for the architects is that there are already ready-made guidelines that can educate their customers. It saves time and money for both the architect and the consumer. Other areas where an architect spends time are explaining the cost of a project, developing partnerships with clients, and discussing the discrepancies between architectural design and entrepreneurial skills. There is a book by Eric Reinholdt's book 'Architect + Entrepreneur' which very intuitively illustrates the same.

2. Networking Opportunities: Any entrepreneur is constantly in search of events and networking opportunities. A variety of MICE events related to architecture in India have taken place in the last five years.

3. Technology: The architects must deal CAD drawings and BIM protocols with extreme care. The architects must also use many methods to handle everyday affairs through several windows. It's a very tedious process. That is where a one-Point interface to manage suppliers, vendors and clients are necessary and hence the need for an enterprise management tool (ERP - SaaS) is felt. This tool must meet the needs, requirements and processes of the Indian people.

\section{Branding, Marketing Opportunities and access to resources}

Architects need a forum for communicating with future customers about their portfolio and success stories.

\section{Continuous Professional Development}

Architecture in India is progressing through developments in innovative technology. Apart from that, the on-ground application of architectural design concepts that is the practical part is way different from classroom theoretical knowledge which is being imparted. To help in coping with architectural, technical and business practical scenarios, a continuous comprehensive professional development is required and is the dire need of the hour. Although we have been slightly able to introduce archipreneur to the progressive ecosystem as they are the building pillars of this ecosystem, still there is a lot more opportunity which could aid in adding more to this developing community? 


\section{METHODOLOGY RESEARCH FRAMEWORK}

The method chosen for the research is looking at the various types of passive income strategies and then analyzing the various case examples.

\section{Research methods}

\section{Literature review}

As this is a fairly new concept, not much research has been done on the passive income strategies. However, the above information in section 2 and section 3 helps create a background on the sources of passive income and how to incorporate it into the architecture profession.

\section{Case examples (secondary case studies)}

Various models were analysed both national and international, to study the patterns and the different ways people have tried to incorporate entrepreneurship into their architectural profession.

\section{Online surveys and expert interviews}

Surveys were conducted to understand the general understanding of the upcoming architects towards the need to engage in passive sources of income, entrepreneurship etc. the expert interviews were conducted to understand the gap between the theoretical approaches towards passive income and real-life situations.

\section{CASE STUDY}

\section{Successful International examples}

1. Jonathan Segal (Hybrid Career); Jonathan Segal's approach has been innovative and unique, by creating a vertically integrated business model. He can finance and make their designs by pursuing a flourishing profession as a developer. Moreover, This unique combination of a career is what has been used by Segal to teach others to follow his path.

2. Eric Reinholdt (Workshop and online Teachings, selling floor plans, writing books); Reinholdt has written a book, Architect + Entrepreneur", through which he aims to inform the reader about his experiences as an " archipreneur" and provide guidance to anyone venturing into this path. Due to this, he is now free to select his time to play with innovative business concepts, his construction practises, 30X40 Design Workshop.

The mix method of having Qualitative and Quantitative methods

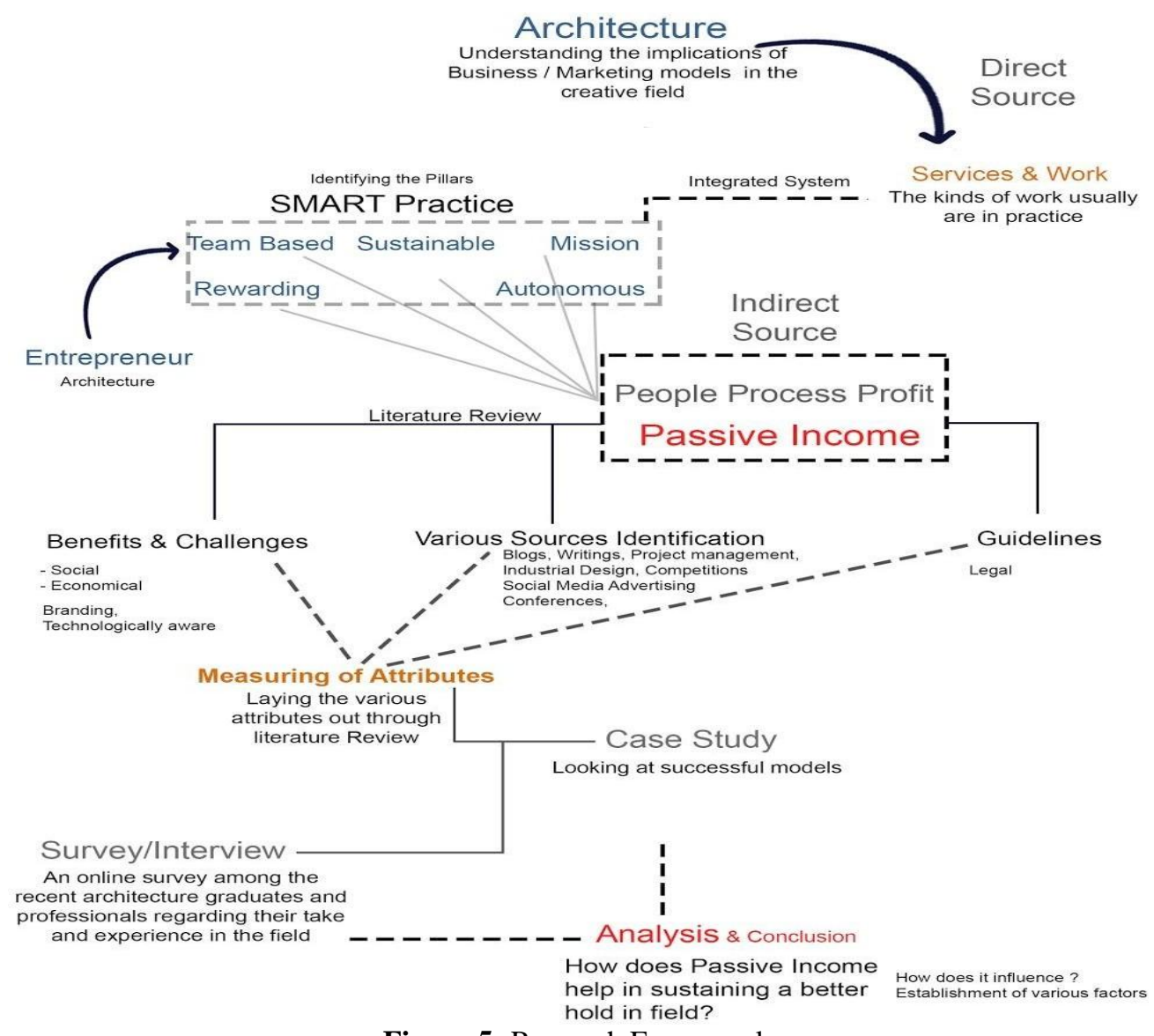

Figure 5: Research Framework 
3. Greg Henderson (Campaigning, fundraising, social practices for development); Architect Greg Henderson creates technology to protect buildings against natural disasters such as earthquakes ever since his graduate school time, His findings encouraged him to further investigate the Magnetic Field opportunities.

\section{Successful Indian Examples}

1. Vijayadurga Koppisetti, Architude: Vijayadurga Koppisetti, originally from Hyderabad, believes that the safety of the environment, the health and well-being of occupants, requires greener solutions. Architude, 2018 is her infrastructure company which aims to provide inexpensively and quickly adopted solutions to green buildings. Architude is designing products and services to encourage innovation, using new-age technology, and offering renewable alternatives to reduce the carbon footprint of the building sector. It has also built an AI which lists suitable and sustainable materials in great detail. The digital design models developed using Architude behave like real-life buildings. From this, we can all extract the cost of construction, time schedules, energy efficiency and the data required to maintain the building.

2. Tithi Tewari, SmartVizX: SmartVizX, Tithi and Gautam Tewari's startup, launched trezi, a full-immersive VR product for the construction business. A one of its kind product, Trezi is a SaaS product and can be instrumental in changing the way design communication happens in the industry. It helps users communicate with co-designers and consumers into the virtual universe in real-time, in interactive settings, and via desktop systems. It helps consumers to thoroughly analyse, study and change their projects.

3. Minal Dubey, Spaciux: Minal Dubey took the archipreneur route, when her startup Spaciux, focuses on content creation for a large variety of practising architects and designers. To focus on documenting their work. Then they also offer social media services via Instagram. Facebook, LinkedIn youtube to help architects attract new potential clients. She has also produced an architecture web series on amazon prime.

4. Tanya Khanna, Epistle Communications: In 2011, Tanya launched Epistle Communications to bridge the gap between design and communication from her house. To fill this void, the startup is a one-of-its-kind agency that provides bespoke strategic marketing consultancy for design, architecture, and related sectors. The start-up has more than 30 customers with design and associated brands. The list contains the top 10 architecture companies from India. It has allowed consumers to be represented in more than 1,800 online and 1,500 print magazines and has helped small and large businesses achieve national exposure and access to new market opportunities.

\section{DATA ANALYSIS AND FINDINGS}

\section{Data Compilation - Analysis and Findings}

\section{Do you think there is a need for a passive income strategy, in the Architectural profession?}

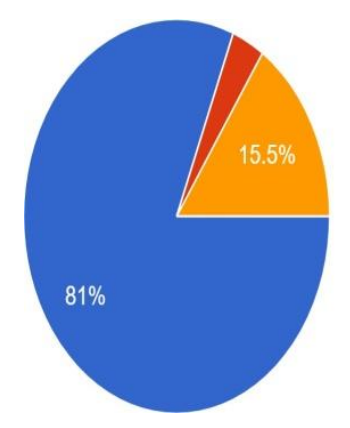

Figure 6: The need for Passive Income

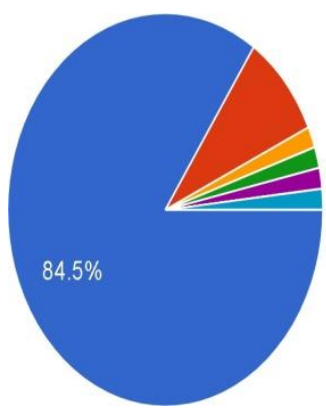

Additional Source of Income Branding Improvisea your contact base and ofcourse helps Financially

Freedom, time.

I feel if the person realises his/her real interest by this method, he or she can opt for this as a specialised field after completing architecture and us...

Building the portfolio

According to the survey conducted, the upcoming architects feel the need to engage in passive sources of income. This is not only to increase the financial source of income but also to generate a nest egg for retirement (Fig 6).

\section{What purpose does passive Income primarily cater to?}

$84.5 \%$ of the participants consider a passive income strategy as a supplementary source of income, while only a small proportion considers it as an opportunity for branding. This shows that currently there is a piece of limited knowledge about the different possibilities of passive income strategies (Fig. 7).

3. Rate the following parameters according to the importance while opting for a passive income strategy? 


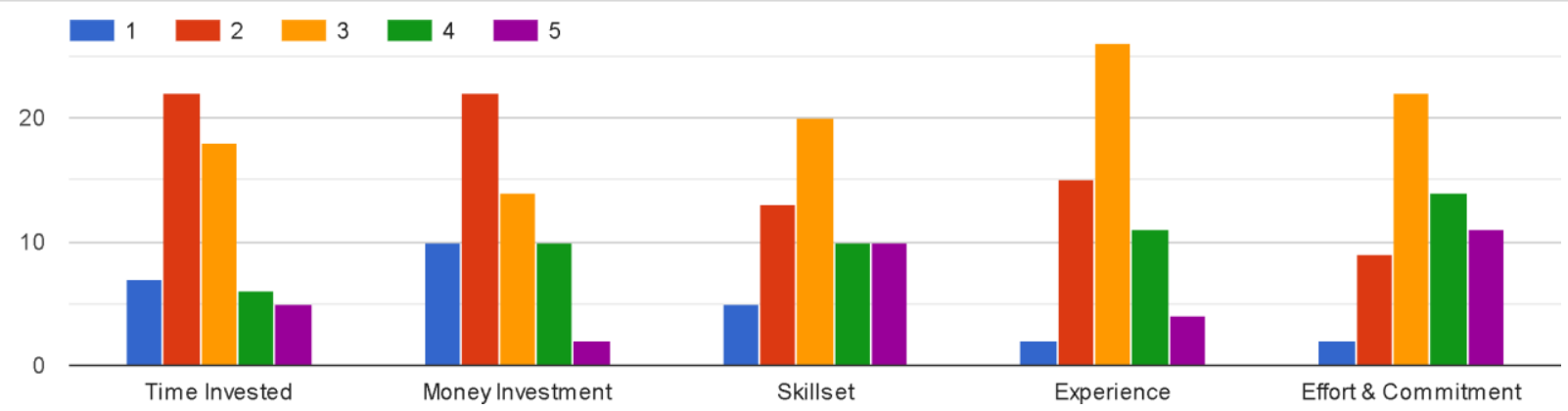

Figure 8: Importance of Parameters of Passive Income

Majority of respondents consider money invested as the primary parameter while deciding on the passive income strategies to be opted for. The second major deciding factor is the time which has to be put and then comes skillset and expectations and effort and commitment respectively. This points to the fact that people still are hesitant to invest a lot of money and not see results. They are less hesitant in investing time though.

Respondents do not consider experience and skill set as vital requirements to start up a passive income strategy. Money and time investment are important, but skill development serves as a mandatory prelude to narrow down on one option.

Another myth associated with a passive source of income is that it hardly requires any effort or commitment on the part of the architect. Even though it comes off as a one-time investment, the initial set up may require extra effort in terms of gathering funding, developing the idea, and so on. Turning a blind eye to the challenges faced while investing in a passive source of income, might end up discouraging the architect, due to which he/she might end up giving it up before it is even established.

\section{To what extent can the architects be labelled as entrepreneurs? And how does passive income supplement}

this role?
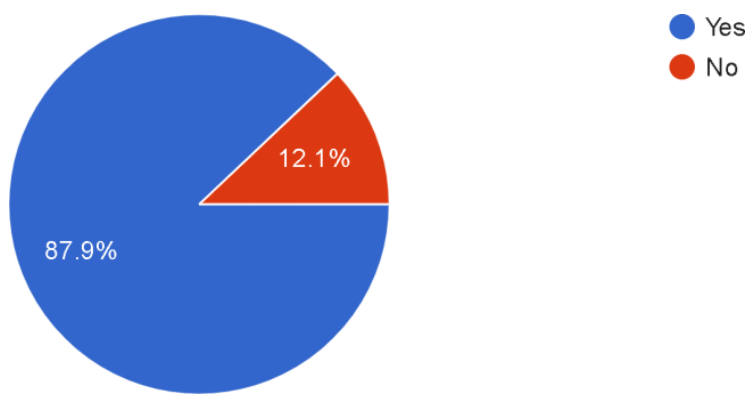

Figure 9: Passive income as an Entrepreneurship
Do you see/consider yourself as an Entrepreneur? 58 responses

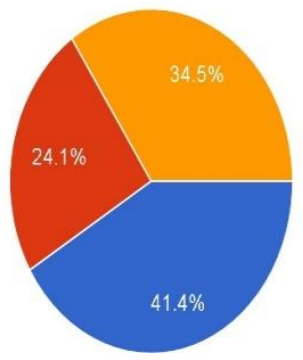

Figure 10: Architects as Entrepreneur

From the responses, it can be stated that many people do consider it as a Passive Income Strategy. It can be thought of as a side practises to generate additional revenue that can be used to ease out one's monetary expenditures and, hence, aid in enhancing the quality of life.

It can be observed that many consider themselves as future Entrepreneurs, they understand the risks associated with it but are still willing to associate themselves with it. Independence and accountability towards themselves and their work is the major appealing factor which attracts them towards Entrepreneurship.

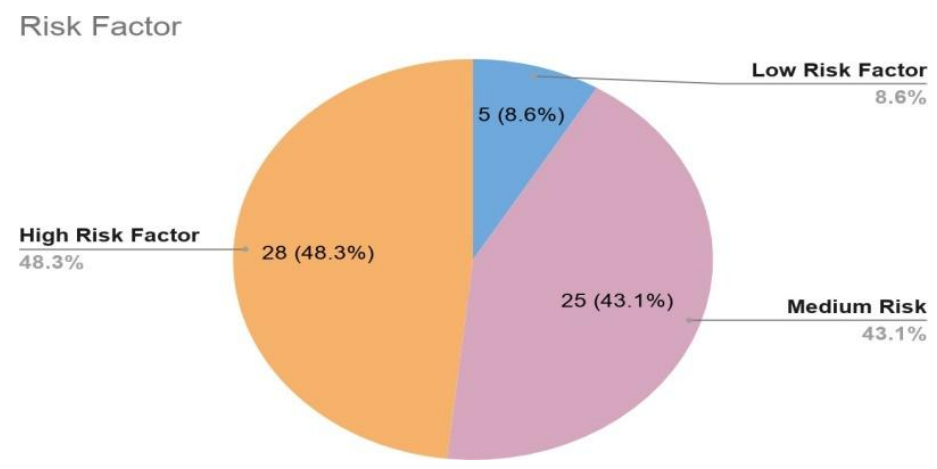

Figure 11: Risk Factor in Entrepreneurship 
Seeing the bar diagram, one could conclude that most of the respondents associate Entrepreneurship as a risky affair. The initial sum, the money invested is normally huge for anyone starting in as an entrepreneur hence they are left in a bit of dilemma to start up with entrepreneurship as a concept and additionally the notion of entrepreneurship is not providing them with the desired stability in terms of their growth which leaves them in a fix.

The Table 1 below showcase the various Passive income strategies and how these strategies can be used with the involvement of the 3 major factors:

- Time \& Effort

- Money Invested

- Skill \& Experience

The following are categories of 3 factors to check the feasibility factor of the various sources of passive income studied during the research.

High

$\bigcirc$ Medium

Low

Table 1: Feasibility Factor

\begin{tabular}{llll}
\hline S. Type of Passive Income & $\begin{array}{l}\text { Time \& } \\
\text { Effort }\end{array}$ & Money Invested & $\begin{array}{l}\text { Skill and Feasibility } \\
\text { Experience Factor }\end{array}$ \\
\hline
\end{tabular}

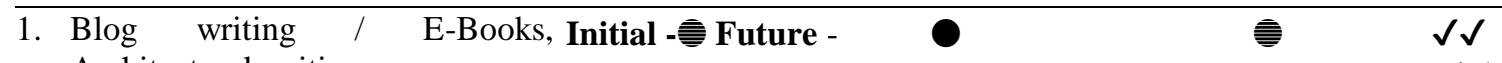
Architectural writing

2. Social Media - Marketing

Initial - 旌 Future -

/ 艕 Depends upon Highly feasible

3. Youtube tutorials, video making

Initial - 틀 Future the firm Branding

\section{$\checkmark$}

After some time if content is monetized, the name is established the work gets 4. $3 \mathrm{~d}$ rendering and services Initial - ⿹ㅡㄹ Future established

\section{Online courses and lectures Initial - 흘 Future} Onlinecourses- general management, marketing, CAD drawing, LEED exams, stability calculations, impact analysis,

$\checkmark$ Feasible

$\mathrm{X}$

Requires frequent effort from the architect. Not very suitable as a passive source of income.

\section{Participating in competitions Initial - 흘 Future}

Requires

Commitment and high effort

7. Indulging in product design Initial - 를 Future Patent the design

8. Taking a stake Construction Initial - Future projects / investing in real estate projects

$\checkmark \checkmark$

Highly feasible

\section{CONCLUSIONS}

\section{Key takeaways from the survey questionnaire:}

The perspective of the upcoming architects regarding a passive source of income

- Currently, there is a limited understanding regarding the opportunities which a passive source of income can offer. It is merely considered an additional source of income, overlooking the branding opportunities it entails. 
- Time and money are considered as the major factors required, to be able to invest in a passive source of income. Skills and experience have not been given much importance, but the case study analysis suggests otherwise. Identifying your strengths and skills is an important component in deciding on the kind of passive strategy you want to invest in. Not understanding the relevance of this factor might reflect on the success of the passive investment.

- Also, even though time is an important factor to consider, it is to be invested in, only during its initial set up. Regular time investment is one of the myths which the upcoming architects associate with.

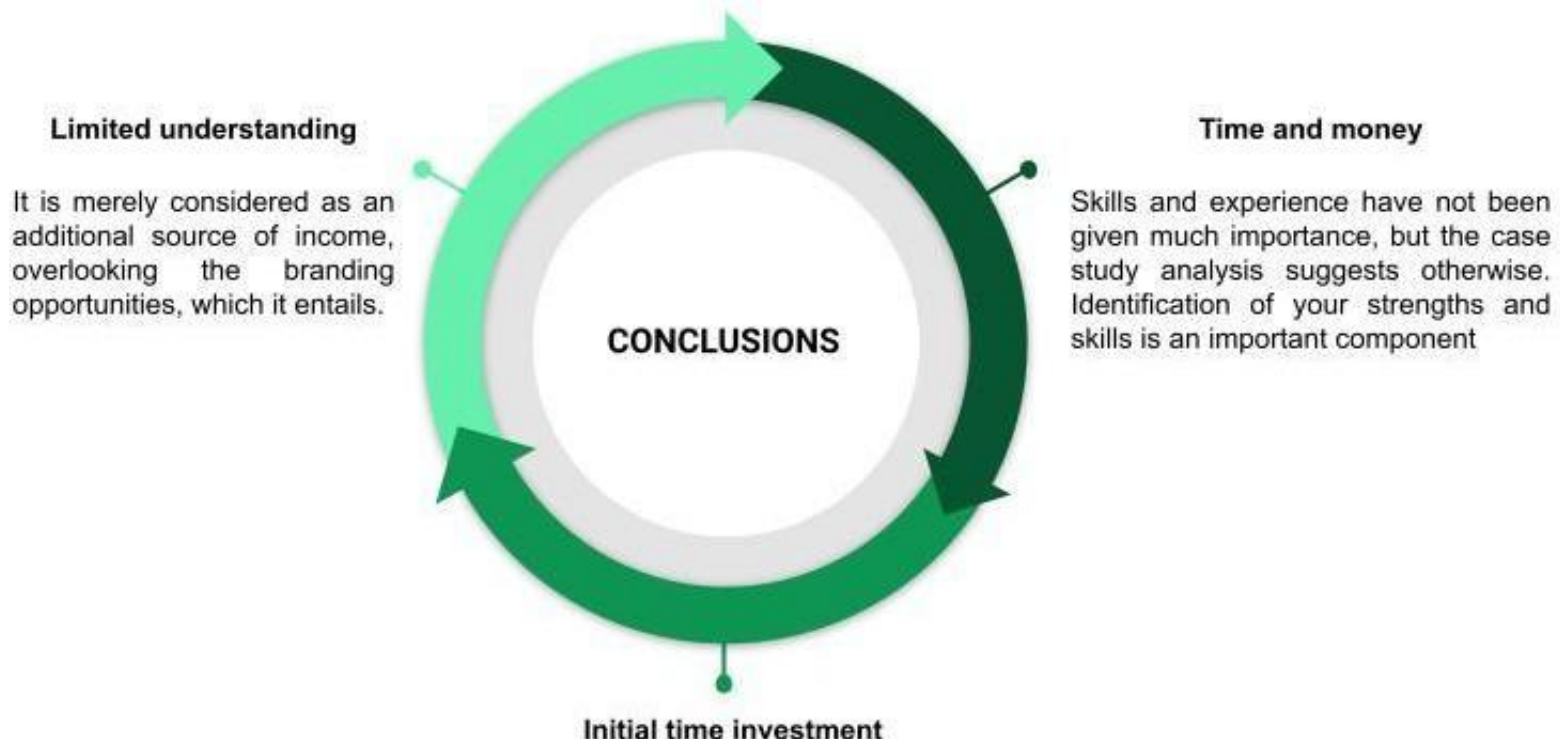

Regular time investment is one of the myths which the upcoming architects associate with.

Figure 12: Key takeaways

- The major consensus favouring passive income turning into an active source of income hints towards a good scope for entrepreneurship among architects. + Also, to venture into interdisciplinary fields and expanding the scope to not be strictly limited to the key contributors to the success of passive income strategies. These are discussed as follows:

\section{Key Observations/Inferences drawn from case studies:}

1. Developing your Project: Jonathan Segal successfully followed the "Architect as Developer" principle. He invested his assets to develop his projects. This is a smart move on the architect's part because generally, architects are bound by the client's demands. The client often controls the process. By opting for a hybrid career, he successfully eliminated the client's interference and became his contractor for the design. Therefore, such a source of passive income can be opted for, which supplements your active source of income. This hints towards the need for architects to indulge in real estate development and become an Archipreneur. Also, this would give the architect greater satisfaction in financial terms. Although the initial projects pose some financial barriers which might come off as demotivating to the architect initially, these can be easily managed once the practice has been established.

2. Combine Architecture With "X": Another example of utilising a passive income strategy to supplement your main practice, as derived from the case studies, would be combining other disciplines. For instance, Vijayadurga Koppisetti combined her technological skills with her architectural knowledge to create an infra tech set up which provides greener building solutions. This can be done with other sets of skills as well. One of the important advantages of architectural training is that it acts as an explorative tool. It doesn't just teach you how to design buildings, but it introduces you to different software, gives you a good grasp in graphics and aesthetics, and so on. Thus, the skills that you learn in your main practice of architecture also push you to create new ideas and some good problem-solving first buyers. Also, starting a blog about architecture would motivate you to learn about new technologies and trends, pushing you to always be aware of what is happening around you in your field.

\section{Finding your Niche}

Architecture is a big field, within itself, and so, it is essential to identify your strengths and your potential audience/ clients. Specialising in a niche will increase your chances of success and it will help you stand out amongst the other competitors. This is a very important step to decide on your passive income as well. In the case studies above, the architects first started by identifying the problems they face as professionals or their clients around them. This gave them a push to develop on an initial idea. For example, Minal Dubey addressed the problems faced by the professionals in the documentation of their work, while Tanya Khanna narrowed down her focus to the challenges of 
communicating the designs efficiently. Therefore, a passive income doesn't just have to benefit you financially, but it can also serve as a payback to your architectural community.

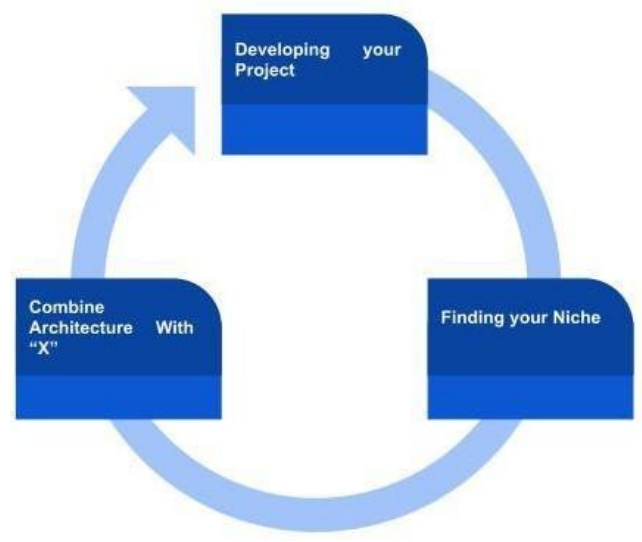

Figure 13: Conclusions

\section{Potential challenges}

\section{Passive income streams don't start passively}

Even though a passive income strategy does not require much effort continuously, it still requires some effort and investment for its initial set up. To assure that your passive source of income runs smoothly and successfully for you to generate a good amount of income from it, you might have to take out some extra hours from your main practice. This is also true in investing money to market your passive source of income to gather enough audience. Therefore, the architect needs to be well prepared for this.

\section{Many passive income streams still require upkeep}

Passive income allows entrepreneurs to explore and have chances to grow and flourish in the field with less investment of time. The concept of passive income generation with new technologies and online ways is still explorative and with less information, it gives chances to have misconceptions around it. Passive income is linked with a high-risk factor with no surety of success with the initial capital investment and effort with all the time invested. This all can be done with a better kind of business development model with proper plans and branding.

\section{REFERENCES}

1. Arora, A. (2020). What is passive income and how is it different from active income?, YourStory.com. Available at: https://yourstory.com/2020/07/passive-income-concept-ways-benefits (Accessed: 4 December 2020).

2. Carpenter, W. (2016). The Passive Way to Passive Income. Lulu Press, Inc.

3. Rattanaprichavej, N. and Teeramungcalanon, M. (2020). An investment decision: Expected and earned yields for passive income real estate investors. Cogent Business \& Management. Edited by P. Foroudi, 7(1), 1786331.

4. 28 Passive Income Ideas You Can Start Today [Make Money 24/7] (2018) Good Financial Cents®. Available at: https://www.goodfinancialcents.com/passive-income-ideas/(Accessed: 25 October 2020).

5. Reinholdt, E. W. (2015). Architect and Entrepreneur: A How-To Guide for Innovating Practice: Tactics, Models, and Case Studies in Passive Income. CreateSpace Independent Publishing Platform. Available at: https://books.google.co.in/books?id=UFV9AQAACAAJ.

6. Young Architect Guide: 6 Proven Ways Architects Can Earn a Passive Income - Architizer Journal (2016) Journal. Available at: https://architizer.com/blog/practice/details/young-architect-guide-passive-income/ (Accessed: 50, 2020).

\section{Appendix - 1}

\section{Questionnaire for an expert interview}

- What are the passive income strategies you have adopted and why?

- Do you think passive income strategies are necessary to run a successful practice? Why do you think so?

- How did you decide upon a suitable passive income strategy for your firm?

- What were the main criteria while deciding upon your strategies?

- Apart from skills and experience, which are the most vital aspects of this profession, according to you, what other aspects should architects possess to sustain their passive income source for a longer run?

- Can passive income turn into an active source of income? 
- What purpose do you think, passive income can be used to cater to

- Since architecture is a vast field with many scopes to discover, do you feel that architects should seek entrepreneurship opportunities in their field?

- Sir/ ma'am is there anything you'd like to tell the young architects how to run a successful architectural practice while also venturing into a successful passive income strategy.

- After being in this profession for a considerable period, have you faced the need to invest in a passive outlet? (to get an idea why it is necessary).

Appendix - 2

\section{Survey Questionnaire}

1. Name*

2. Age $^{*}$

○ 17-24 (Clg Student)

○ 24-30 (Recent Graduate/Professional)

○ 30-45 (Young Professional)

○ 45- 60 (Senior Professional)

○ 60 and above (Senior Professional)

3. Professional Field*

○ Student

○ Own Practice/Self-employed

○ Unemployed

4. Gender ${ }^{*}$

○ Female

- Male

- Prefer not to say

5. Do you think there is a need for a passive income strategy, in the Architectural profession? ${ }^{*}$ Passive income is money earned from any venture with a minimal operation that needs little regular effort or maintenance on the part of the person.

○ Yes

○ No

○ Other

6. Mention any, passive income which you are aware of ?*

7. What purpose does passive Income primarily cater to?

- Additional Source of Income

○ Branding

8. Rate the following parameters according to the importance while opting for a passive income strategy ${ }^{*}$

\begin{tabular}{lllll}
\hline Pointer & 1 & 2 & 3 & 4 \\
\hline Time Invested & 0 & 0 & 0 & $\bigcirc$ \\
\hline Money Investment & 0 & 0 & 0 & $\bigcirc$ \\
\hline Skillset & 0 & 0 & $\bigcirc$ & $\bigcirc$ \\
\hline Experience & 0 & 0 & 0 & $\bigcirc$ \\
\hline Effort \& Commitment & 0 & 0 & 0 & $\bigcirc$
\end{tabular}


9. Do you think Entrepreneurship can be treated as a Passive income strategy?*

○ Yes No

10. Do you see/consider yourself as an Entrepreneur?*

○ Yes

○ No

- May be

11. How would you rate Entrepreneurship in terms of risk factor?" 1 being Least Important and 5 being very Important

\begin{tabular}{lllll}
\hline 1 & 2 & 3 & 4 & 5 \\
\hline 0 & 0 & 0 & 0 & 0 \\
\hline
\end{tabular}

Appendix - 3

\section{Expert interviews}

\section{Question and Answer- Ar. Anil Bhatia}

\section{Q1) What are the passive income strategies you have adopted and why?}

Passive Income is that which would require a very minimal amount of time and effort. It was mainly through the rental source of income, and of course the share market investments earlier. But with the growing knowledge and advancements in technologies in the current times, I do have to make vlogs and youtube videos as initial investment my passive source for a later age.

\section{Q2) Do you think passive income strategies are necessary to run a successful practice and why do you think so?}

Yes, very much. Around 25 years ago, I had only one client as Appughar, Chief Architect. But due to some client issues, my contract was eradicated. That was when I realized that there should be variety in the types of work you do with different clients. So that you have a backup as a shock absorber. I realised the need to have a backup in life, a kind of side hustle but in terms of passive income so that once I invest I can get off money through it.

Q3) How did you decide upon a suitable passive income strategy for your firm or individual? Passive income is for individuals based mostly and what all is done on company based is an active source for them. So on an individual level according to me what affects most is having a good strategy based upon your interest and skills.

Choosing the suitable passive income depends upon if that is a long-time good investment, like the rental income, is a legal and reliable source. Then making videos help in branding too so it's good for my firm getting recognition

Q4) What was the main criteria while deciding upon your strategies?

I do this and believe that this depends upon the skill one possesses and the time and money they are ready to invest.

And one should understand that it's really important to invest; however small an amount as an individual you earn you should start investing at the youngest age possible.

Q5) Apart from skills and experience, which are the most vital aspects in this profession, according to you, what other aspects should architects possess to sustain their passive income source for a longer run?

Savings, Totally saving. Because as much as you save is your future income. In the field of architecture, the driving source to generate passive income

For the upcoming generation, we have all this happening over the global network on the internet. By doing something online once and then it grows up and manifolds. By having some efforts and maintenance within the required time.

\section{Q6) Can passive income turn into an active source of income?}

That's exactly as we discussed, there are these online courses and blogs and marketing happening online that people are shifting and making that as their full-time source of income with architecture as a consultant service for them.

So yes surely, Passive income if doing great can be converted as an active source of income which with better efforts can help make it flourish and have a better name in the industry.

\section{Q7) What purpose do you think, passive income can be used to cater to.}

For the betterment and the growth of the individual to the growth of the profession and community. It's about giving back to a society of course after catering to your needs and family. These side ventures provide a passive source of income and caters to developing skills and help in having a thing working on autopilot mode to have a future income.

Q8) Since architecture is a vast field with many scopes to discover, do you feel the need architects to seek entrepreneurship opportunities in their field. 
It is very much necessary in the field. As pure architecture is not going to give you enough money to have a sufficient amount of needs. One needs to start thinking about it at an early age to help them sustain themselves sooner and better. Finding solutions to people's problems as architecture is all about catering to users' experience and their surrounding environment needs.

\section{Question and Answer- Ar. Tushar Agarwal}

\section{Q1) What are the passive income strategies you have adopted and why?}

The passive income generation adopted was mostly through teaching, creating videos and publishing a few papers for product development for many global companies. These strategies were adopted because they always had an inherent interest and enjoyed investing time in it, also helped enhance knowledge while doing these activities.

\section{Q2) Do you think passive income strategies are necessary to run a successful practice and why do you think so?}

They do not think that passive income strategies are required for running the practice. It's a different scenario altogether as of now. For the last couple of years in the architecture profession, the whole architecture field in India and abroad has been under so much pressure that passive income is felt. Plus adding to it, if a particular firm is running low on funds/money to sustain the firm, ideally the firm should shut down as passive income can meet the requirements of an individual as a 'pocket money' source of income, it cannot help to run a firm.

Otherwise, 15 years back the architecture profession was in a better situation. There was no need for passive income. Quality of life, personal needs, aspirations and their changing definitions with time all call for passive income these days.

\section{Q3) How did you decide upon a suitable passive income strategy for your firm?}

There isn't a passive income for the firm as such. Passive income is for personal requirements, which can be labelled as an individual's pocket money, which is generally used to ease personal monetary burdens.

The main business is the manufacturing of interior fitment Elements, which is related to the purely architecture and interior designing industry, which is specific to architecture core industry, and passive income generation strategies specific to one's interest like in this case, teaching in different schools, making manufacturing videos, preparing design courses for furniture, setups and consultancy for setting up furniture manufacturing industries.

Q4) What was the main criteria while deciding upon your strategies?

Interest and most important having fun in doing it, as then work seems fun.

Q5) Apart from skills and experience, which are the most vital aspects in this profession, according to you, what other aspects should architects possess to sustain their passive income source for a longer run?

Firstly, we are not commercially inclined and we are not given education regarding the commercial aspects of running an office. Any beginner has a very less understanding of the commercial aspects of running an architectural practice as no one teaches it because of which one lacks in practicality concerning the business. Then commerce aspect also comes into play which also gets missing as it's also not much talked about, which is the most important factor.

\section{Q6) Can passive income turn into an active source of income?}

Need for passive income arises because one's active income isn't able to sustain the requirements of that person. Personally, that is my opinion for an income-producing activity that it has to be a different business altogether not related to architecture and Architectural practices. Otherwise, the same thing will happen and you might end up not gaining from either of them.

\section{Q7)What purpose do you think, passive income can be used to cater to.}

From his point of view, it can only cater to if we are talking about the owner of an architectural firm. The passive income generation can only help him to reduce his remuneration burden on his company

Q8) Since architecture is a vast field with many scopes to discover, do you feel the need architects to seek entrepreneurship opportunities in their field.

I am $100 \%$ second because there is no other way. There is no other way. From presentation to manufacturing/production, there is a huge gap. To bridge that gap one needs to identify which entrepreneurship activity one can identify and associate with, to sustain and secure themselves in future. 